\title{
Analogical Thinking for Generation of Innovative Ideas: An Exploratory Study of Influential Factors
}

\author{
Eunyoung Kim and Hideyuki Horii \\ Center for Knowledge Structuring, \\ The University of Tokyo, Tokyo, Japan
}

\author{
ekim@ischool.t.u-tokyo.ac.jp; horii@civil.t.u-tokyo.ac.jp
}

\begin{abstract}
Analogical thinking is one of the most effective tools to generate innovative ideas. It enables us to develop new ideas by transferring information from well-known domains and utilizing them in a novel domain. However, using analogical thinking does not always yield appropriate ideas, and there is a lack of consensus among researchers regarding the evaluation methods for assessing new ideas. Here, we define the appropriateness of generated ideas as having high structural and low superficial similarities with their source ideas. This study investigates the relationship between thinking process and the appropriateness of ideas generated through analogical thinking. We conducted four workshops with 22 students in order to collect the data. All generated ideas were assessed based on the definition of appropriateness in this study. The results show that participants who deliberate more before reaching the creative leap stage and those who are engaged in more trial and error for deciding the final domain of a new idea have a greater possibility of generating appropriate ideas. The findings suggest new strategies of designing workshops to enhance the appropriateness of new ideas.
\end{abstract}

Keywords: analogical thinking, idea generation, innovation workshops, thinking processes in idea generation, assessment of new ideas

\section{Introduction}

Despite their tremendous contribution to technological or theoretical innovation, academic institutions have been criticized for being insensitive to the rapid changes in the real world; moreover, they neglect the realities (Kogan, 2000; Minogue, 1973). In response to these criticisms and social needs, in the last few decades, a number of research centers and departments have been founded, focusing on new idea generation as a strategy for coping with social changes. In response to the increasing needs for facilitating generation of new ideas, many academic institutions provide educational programs

Material published as part of this publication, either on-line or in print, is copyrighted by the Informing Science Institute. Permission to make digital or paper copy of part or all of these works for personal or classroom use is granted without fee provided that the copies are not made or distributed for profit or commercial advantage AND that copies 1) bear this notice in full and 2) give the full citation on the first page. It is permissible to abstract these works so long as credit is given. To copy in all other cases or to republish or to post on a sreferver or to redistribute to lists requires specific permission and payment of a fee. Contact Publisher@InformingScience.org to request redistribution permission.

\section{promoting innovative idea generation.}

Definitely, innovative ideas allow us to solve complex problems that cannot be solved by traditional, routine, or common methods. Creating novel solutions to problems has fascinated many researchers in diverse disciplines. There is a wide range of approaches in perspective of cognitive, clinical, social, organizational, educational, historical, cultural, 
managerial, and personal areas. In spite of the tremendous amount of work on innovation, we still lack understanding of how to evaluate innovative ideas and what kinds of thinking processes encourage innovativeness. This paper proposes an effective evaluation method for assessing new ideas, as well as identifying factors that enable generation of appropriate ideas, focusing on idea generation using analogical thinking. In order to fulfil the objectives of this research, it is important to establish theoretical backgrounds by reviewing relevant studies on analogical thinking and thinking process to develop an effective evaluation method. More importantly, this study empirically investigates factors influencing generation of innovative ideas with data collected from four workshops.

\section{Analogical Thinking for Idea Generation}

To some extent, everyone uses analogies as a thinking mechanism in daily life (Holyoak \& Thagard, 1996). Analogical thinking is the cognitive process of transferring information or meaning from a particular subject (the source) to another one (the target). Welling (2007) defines analogical thinking as such that "implies the transposition of a conceptual structure from one habitual context to another innovative context", where "the abstract relationship between the elements of one situation is similar to those found in the innovative context" (p.168). Glynn, Britton, SemrudClikeman \& Muth (1989) defined analogy as serving an explanatory function when it puts new concepts and principles into familiar terms. Analogy serves a creative function when it stimulates solutions of existing problems, identification of new problems, and generation of hypotheses.

\section{Analogical Thinking for Creative Problem Solving}

Numerous previous studies have supported the idea that analogical thinking plays a central role in creative idea generation because it can foster insights into new domains by analogizing to prior knowledge (Finke, Ward, \& Smith, 1992; Gentner et al., 1997; Hesse, 1966; Holyoak \& Thagard, 1989; Koestler, 1964; Perkins, 1997). Boden (1994) stated that creativity in psychological theory needs to describe how analogical thinking works. Clement (2008) examined sources of creative scientific theory formation in the domain of non-formal reasoning. He observed that analogies are frequently used by scientists in problem solving. Gick and Holyoak (1980) conducted five experiments with university students, having them solve a radiation problem, the same problem used in Duncker's (1945) original experiment. In one of their experiments, 27 subjects were given a story analogy and two irrelevant stories before they were presented with the problem to be solved. Meanwhile, twelve of them were instructed to use those story analogies to solve the radiation problem; but in the other group, fifteen subjects were not given any hint to utilize those story analogies for problem solving. As results, they found that $92 \%$ of those in the first group solved the problem, while only $20 \%$ in the second group were able to find the solution.

The power of analogical thinking is to reveal common structures and to import structure from a well-articulated domain into a novel domain, which makes it the foremost instrument of major theory change (Gentner et al., 1997). Holyoak, Lee, and Lu (2010) defined analogical thinking as focusing on abstract relational categories. However, analogical thinking often misleads us in creating innovative solutions. Rather than creating novel ideas, we use analogical thinking as an alternative to hard thinking (Holyoak \& Thagard, 1996). Goldschmidt (1995) affirmed that the carrying over of surface features only, without a structural similarity to underpin them, may lead to a false analogy and consequently to a wrong solution to the problem.

\section{Structural and Superficial Similarities}

Blanchette and Dunbar (2000) claimed that analogies are generated by superficial or structural similarities from the memory. They conducted three experiments with 49 subjects, 12 subjects, and 22 subjects respectively. In the first two experiments, 12 groups of subjects and 12 individual 
subjects were asked to generate as many analogical sentences as possible in twenty minutes regarding the topic of the zero-deficit issue. Before starting, they were given instruction on how to use analogies, e.g., "The deficit is like cancer, you have to get rid of it. Also, it multiplies if you don't take care of it." In the third experiment, subjects were given various stories to read; after a while, they were asked to read new stories and to say which of previous source stories they were reminded of by the new stories. To analyze the data, all the generated analogies were categorized based on the semantic features of the domain, such as economic/politics, animals/farming, illness/medicine. In this research, superficial similarity means the resemblance between the semantic category of analogies generated and the target domain of zero-deficit issue. Structural similarity refers to the resemblance in the underlying systems of relations between the elements of the sources and the elements of the target. For example, a participant generated an analogy such as "If you stop giving pesticide to your apples, then all your apples die. Likewise, if you cut social programs, then negative consequences follow." Here, two statements have a common structure in terms of the relation of elements in the sentence. The main finding of this research is that the generation task motivated people to use more structural similarity, while in the reminding task people used predominantly superficial features. This study revealed that in the generation task of the first and second experiments, people used analogical sources that did not have superficial features in common with the target. Most of the analogies were generated from non-superficial features of a given target (66.7\% in the first experiment; $80.6 \%$ in the second experiment) while most of them used structural similarity ( $78.1 \%$ in the first experiment; $89.7 \%$ in the second experiment). However, when the task was changed to a reminding task, $65 \%$ of retrievals were based on surface similarity, while only $16 \%$ were based on structural similarity.

Intra-domain analogies are based on both superficial and structural similarities between the target and the sources, whereas inter-domain analogies are based only on structural similarities (underlying principles) between the target and the sources. Creative idea generation through analogical thinking needs to use structurally similar analogies but not superficially similar ones; In other words, cross-domain analogies enable us to generate more novel ideas than within-domain analogies. Many studies suggest that using a structure-mapping framework, structural similarity can be identified by matching or relating each element in one idea to the other idea (Falkenhainer, Forbus, \& Gentner, 1989; Forbus, Ferguson, \& Gentner, 1994; Forbus \& Oblinger, 1990; Gentner, 1983). The process of structural comparison acts as a bridge by which similarity-based processes can give rise to abstract rules (Gentner \& Medina, 1998). Analogical thinking lead us to form a schematic structure in which the object is replaced by variables, while retaining the common relations (Winston, 1982). For producing innovative ideas, the use of analogy needs to be accompanied by structural analysis. In addition, it is important to apply those structures to novel situations for constructive thinking through analogy.

\section{Assessment of Thinking Processes and Ideas Generated}

Despite all of the attention to new idea generation, the method of assessing new ideas is still problematic. It has been acknowledged that creativity is one of the most complex human functions and also one of the most difficult psychological constructs to define and measure (Hocevar, 1981). For this study, it is important to examine existing approaches to assessing new ideas generated and analyze their pros and cons to develop an evaluation method. In addition, to identify the thinking process that enhances the appropriateness of generated ideas, this section also reviews current arguments on the thinking process of idea generation.

\section{Drawbacks of Existing Assessment Methods}

The present methods of measuring creativity or appropriateness of new ideas are controversial because they involve subjective judgments, are time consuming, lack comprehensiveness, and 
adopt instruments that have no theoretical grounding. Researchers have been dissatisfied with definitions related to the creativity or innovativeness of new ideas, as well as evaluation methods of assessing new ideas.

In practice, companies or designers usually evaluate the innovativeness of ideas by having a small group of experts rate them according to some criteria, which are defined as attributes based on the purpose of idea development. However, there is no guarantee that judges will understand and apply the sometimes complex definitions in rating, and there is little research showing that instructions even make a difference (Hocevar, 1981). In past studies, numerous kinds of measures have been used to evaluate ideas, and each measure has its own set of limitations. For example, in the single-dimension measures of idea evaluation, raters may consciously or unconsciously include multiple constructs in a single rating (Dean, Hender, Rodgers, \& Santanen, 2006). On the other hand, for multidimensional measures, raters also may consciously or unconsciously be influenced by other dimensions or sub-dimensions. Furthermore, even if the judges are provided with evaluation guidelines, they may have personal biases, different points of view, and deviating standards.

On the other hand, several studies have tried to evaluate the novelty of ideas with less subjectivity. Connolly, Jessup, and Valacich (1990) focused on the rarity in assessing the novelty of generated ideas. They conducted computer-based group brainstorming with 72 students to generate ideas for solving the problem of parking on campus. The rarity was determined by counting the number of subjects who proposed the same idea, i.e., the fewer number of subjects proposing the same idea, the higher its rarity score. However, this approach has limitations because the result will differ if the number of ideas in an idea pool changes, and it is not easy to differentiate a given idea from those that are repetitive or slightly different.

To evaluate the generated ideas from analogical thinking, it is necessary to examine the similarities and differences between elements (Berlyne, 1960). As mentioned in the previous section, the similarities in analogical thinking are divided into "superficial similarities" and "structural similarities". Blanchette and Dunbar (2000) outline a method for assessing superficial and structural similarities in analogies. However, their evaluation method does not account for the appropriateness of generated analogies. According to their study, superficial similarities are judged by the semantic resemblance between the source and the target in terms of their domain. For example, if the source analogy addresses the importance of nutrition in planting (which is semantically categorized as "farming") to emphasize the importance of social welfare budgeting (categorized as "economics/politics") as the target, the domain of source is superficially far from that of the target, which is the zero-deficit policy. For assessing structural similarities, they identified ten categories through grouping based on the underlying structures of analogies between the source and the target. In their experiment, 11 source analogies were generated based on the structure of "If cut $X$, then negative consequence", which corresponds to "if we cut budget for social programs, then negative consequences" in the target. On the other hand, 28 out of 128 generated analogies did not have common relational structures between the source and the target.

\section{Myths on Thinking Process for Idea Generation}

In many studies, the 4Ps (Person, Process, Product, and Press) are a widely accepted framework for explaining the factors essential for creativity (Rhodes, 1961). Amongst the 4Ps, this study focuses on the process of thinking, which is more open to instruction and analysis through workshops. Regarding the thinking process, people used to believe that creative ideas come from sudden moments of insight that involve the subconscious mind. Many with this belief argue that we tend to think ideas emerge spontaneously, from the unconscious mind of the creator. Creativity may sometimes be significantly influenced by serendipity, chance, and accidents (Runco, 2014). 
In the field of creative design studies, the "creative leap" is a significant concept, often reported as arising in sudden illuminations (Cross, 1997). In a design process, the creative leap is characterized as a sudden perception of a completely new perspective on the situation different from what we previously understood (Dorst \& Cross, 2001). The creative leap can be identified as a point during the ideation process where the key concept (or element) begins to emerge. Retrospective accounts of creative moments in ideation given by participants themselves may not by perfectly reliable. However, some empirical studies of creative design focused on this creative leap moment. For example, Akin and Akin (1996) focus on the analysis of the "Ah-ha!" moment, which is a well-known phenomenon of creativity arising from a sudden realization. While generating an idea, creators probably have experience of sudden illumination - the creative leap or mental leap. For example, in creative design tasks, designers may clearly recognize breakthroughs or significant points of conceptualization, exclaiming "Ah-ha!", "Eureka!" or "Good idea!" Cross (1997) points out that the sudden illumination is more like building a "creative bridge" between the problem and the solution space, and that the expression of concept actually accumulates through a lot of prior notions, examples, and discussion.

However, in this study, the creative leap stage is taken as an insight or a distinguishable moment driven by a series of analogical thinking, not as pure serendipity. The creative leap moment should be considered as a result of smooth and incremental build-up from previous ideas or of a sudden extraordinary break from previous ideas during the thinking process.

\section{Method}

The objective of this study is to investigate innovative idea generation through analogical thinking, specifically to identify factors enhancing the appropriateness of new ideas generated by observing the thinking process. A training workshop was conducted to collect research materials on analogical thinking for idea generation, and participants were interviewed afterwards to gather additional data. An improved method of assessing new ideas was proposed, and an instrument for measuring idea appropriateness was developed for data coding and analysis. The major methodological components of this study are each documented below in subsections.

\section{The Innovation Workshops: Subjects and Data Collecting}

The workshop was conducted four times in a classroom, each time with a different group of attendants. In total, 22 university students ( 15 males, 7 females) from 14 different countries participated in the workshop between 2014 and 2015. Depending on the number of participants in each workshop, they were grouped with two or three people of diverse backgrounds in terms of major, sex, and nationality. These participants were recruited as volunteers from related courses in the department of engineering by emailing students to call for participation in the innovation workshop for research. The subjects were recruited and informed regarding the innovation workshop via emails. The theme of the workshop was to create new services based on collective intelligence.

The innovation workshop consisted of a preparatory task and two main tasks. The preparatory task was to acquire knowledge on the existing business cases. All subjects had to read the case material of 25 collective intelligence services including well-known services such as Amazon.com, or Google Japanese input, as well as services unfamiliar to the participants but popular in Japan, such as Tabelog, or @ Cosme. The first main task was a categorization task for understanding the underlying mechanism of the existing services, and the second main task was an idea generation task for creating new service ideas using analogical thinking based on the categorization they had created in the previous task. Each participant was asked to create new service ideas using analogical thinking sourcing from the title of the category as well as the selected cases by his or her preference. Subjects had to complete both the categorization and generation tasks each within one hour, and there was a 15-minute break between the two task sessions. The 
categorization task was performed by group discussion, while the generation task was performed individually.

\section{Assessment of New Ideas}

Of the new idea generated through analogical thinking, there are two distinct dimensions: superficial and structural analogies (Blanchette \& Dunbar, 2000; Dunbar \& Blanchette, 2001). Many authors argued that structural similarity is the crucial defining feature of analogical thinking. If an idea is created based on a structural similarity with the source idea, it increases the likelihood to take advantage of the effective mechanisms already demonstrated. However, this approach does not guarantee the appropriateness of generated ideas. To generate an appropriate idea, one is expected to keep the structural similarity but to be superficially different from the already existing cases. In other words, when participants are instructed to use analogical thinking to generate ideas, they should be working in a domain far from the already existing ones, but retain one of the existing mechanisms.

In this study, a new idea with high structural similarity but low superficial similarity with the existing cases is considered appropriate. Consequently, the appropriateness of a new idea is evaluated in terms of superficial and structural similarities.

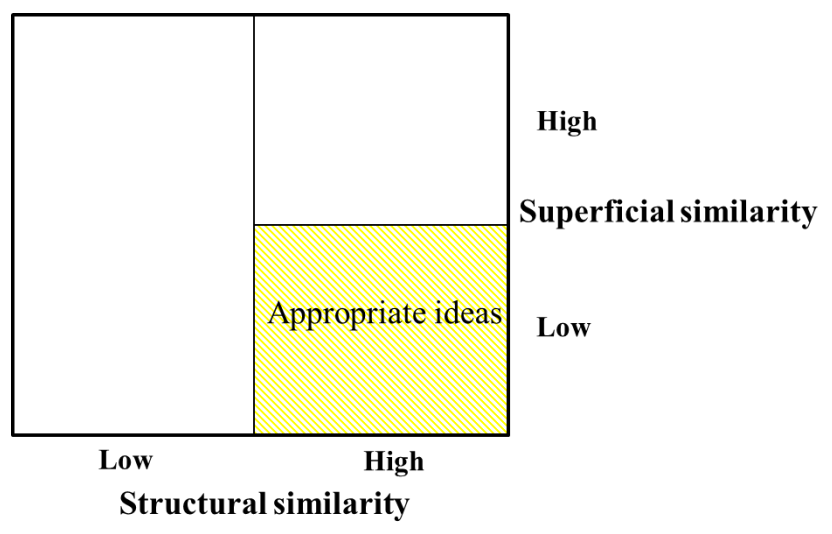

Figure 1: The proposed evaluation method

As shown in Figure 1, the highlighted quadrant is for the generated ideas representing the deep structure of source cases in a semantically different domain, i.e., it has low superficial similarity and high structural similarity with the source cases. This area means that participants could generate an appropriate idea by importing structural features from the example cases and applying them in a different domain. On the other hand, if an idea is generated with implication of the structural features of source cases but in a similar domain, or if the idea does not have a structural similarity with existing cases, the generated idea is not appropriate.

With the dimensions of evaluation defined, the scale of assessment on each dimension must be developed. Structural similarities were judged by investigating if the new ideas were generated using the underlying structures of source ideas or not. Since collective intelligence service was the main topic of the workshop, the exemplary structures in collective intelligence services were determined. Four researchers in the innovation science study group categorized the 25 cases individually and created 26 category labels. These 26 category labels were classified into four groups by cluster analysis: 1) Crowdsourcing; 2) Human computation; 3) Social computing; and 4) Data mining (see Appendix). Further, this classification of the underlying structures in 25 cases was supported by related research on classification of collective intelligence (Devadasan, 2011; Malone, Laubacher, \& Dellarocas, 2009; Quinn \& Bederson, 2011). 
Superficial similarities were measured by semantic similarity between the domains of source cases and the created idea, using a latent semantic analysis application (http://sa.colorado.edu). Latent semantic analysis (LSA) is a statistical technique for extracting and representing the similarity of meaning of words and passages on a large body of texts. The raw data for LSA are meaningful passages and the set of words, and a matrix is constructed with words in columns and documents in rows. The cells of the matrix are the frequencies words occurring in each document. The data set fed into the LSA application is a corpus of about 11 million words, yielding a matrix of more than 92,000 unique keywords and more than 37,000 documents (Kintsch, 2001). To compute semantic similarities of the domains between the sources and the new idea in the corresponding structure, keywords obviously describing services, products, or targeting users without ambiguity - which constitute the domains in each business case - were selected.

\section{Data Coding and Analysis}

Subjects were asked to bring their own laptop for the workshop to connect to the shared screen and to carry out the tasks using APISNOTE - a software specifically developed for the innovation workshop. In its records, APISNOTE tracks each note with the actual time of its creation in the "hh:mm:ss" format, which enables us to analyze the thinking process based on the content of notes produced during the generating task session (see Figure 2). It is a powerful tool not only for collaborative information processing, but also for recording the thinking process at the individual level. It allows participants to record their ideas as notes and share with others who are connected to the network. During the categorization task session which requires group discussions, APISNOTE displayed notes on a large shared-screen. The entire workshop process was video recorded with 360-degree cameras.

a)

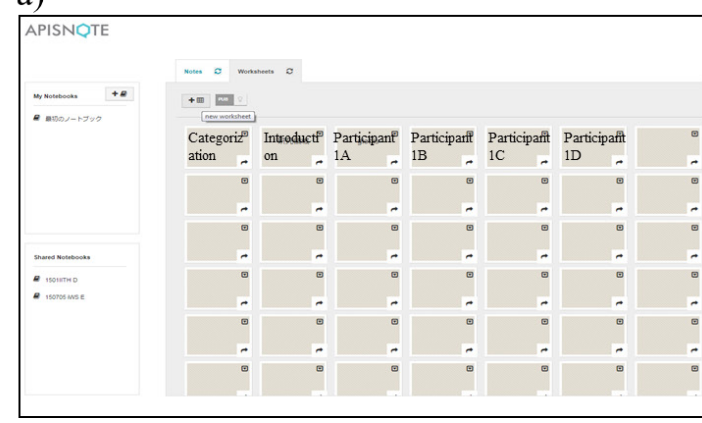

b)

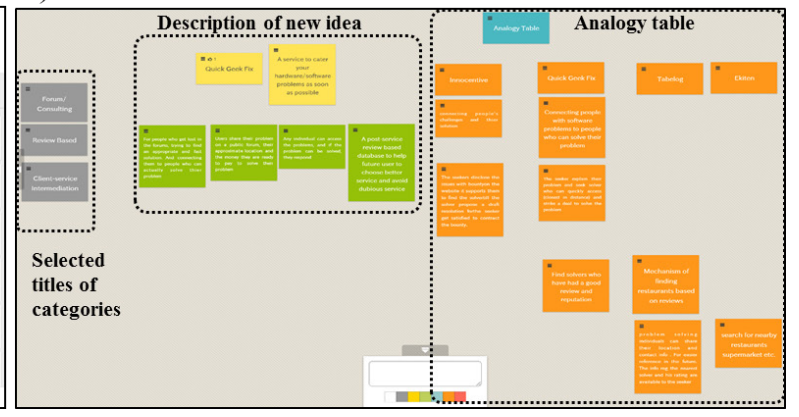

Figure 2: (a) Worksheet created by APISNOTE;

(b) Notes by a participant for idea generation

After the workshop, subjects were asked to retrace their ideation process using the cues provided by APISNOTE showing the history of ideation process along with the time stamped notes they created during the workshop. Face-to-face interviews were conducted to have participants reflect on how they generated each note using APISNOTE. Then they were asked to indicate the creative leap stage (in reference to a specific note) during the idea generation session (see Figure 3).

It seems reasonable to suspect that a participant's performance of idea generation may be correlated with the time taken and effort made prior to reaching the moment of insight. Therefore, it is important to investigate the thinking process while generating new ideas, and thinking process was revealed by analyzing records from APISNOTE and interview transcripts. Based on the record in the APISNOTE, each note was coded into a sequence of "mechanism of the service", "source retrieval", "domain setting", "domain refining", "title of a new idea", and "others" according to its content, using a color coding scheme. In addition, "creative leap" as indicated by each subject during the interview was marked red on the process bar (see Figure 4). 


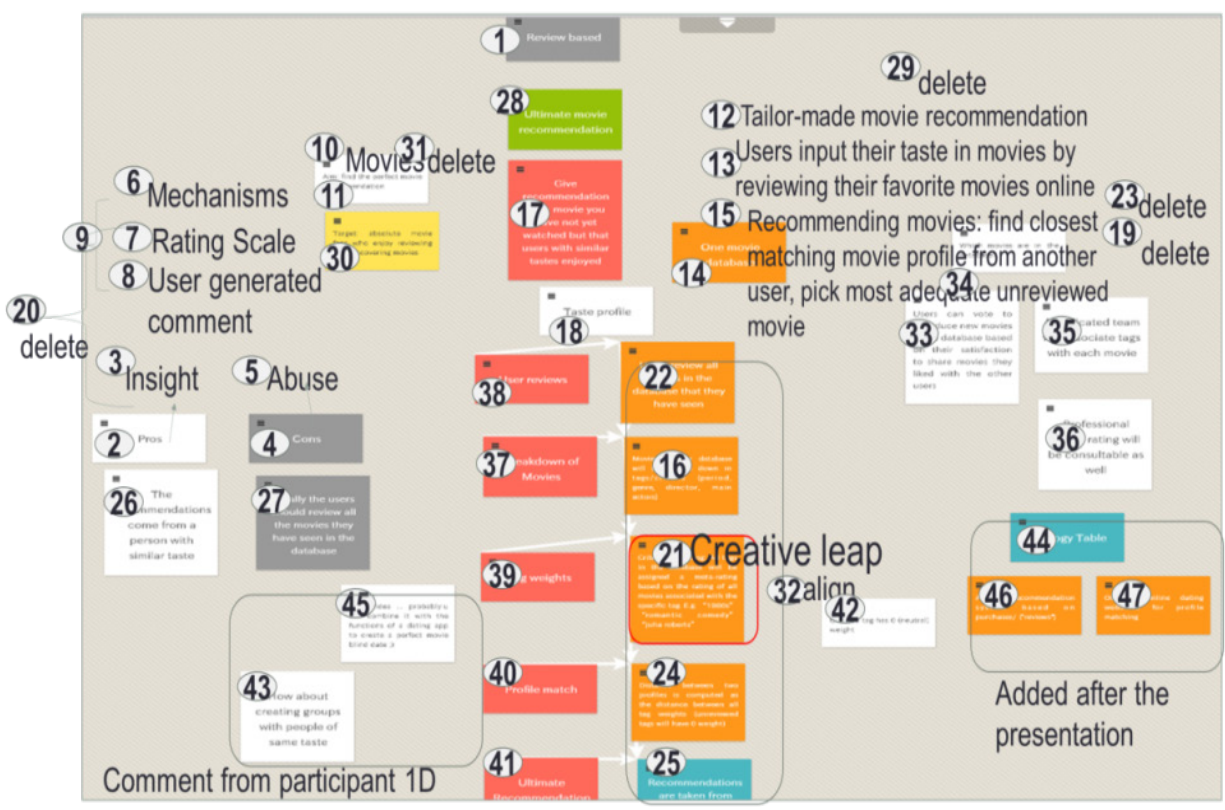

Figure 3: Ideation process as shown in APISNOTE
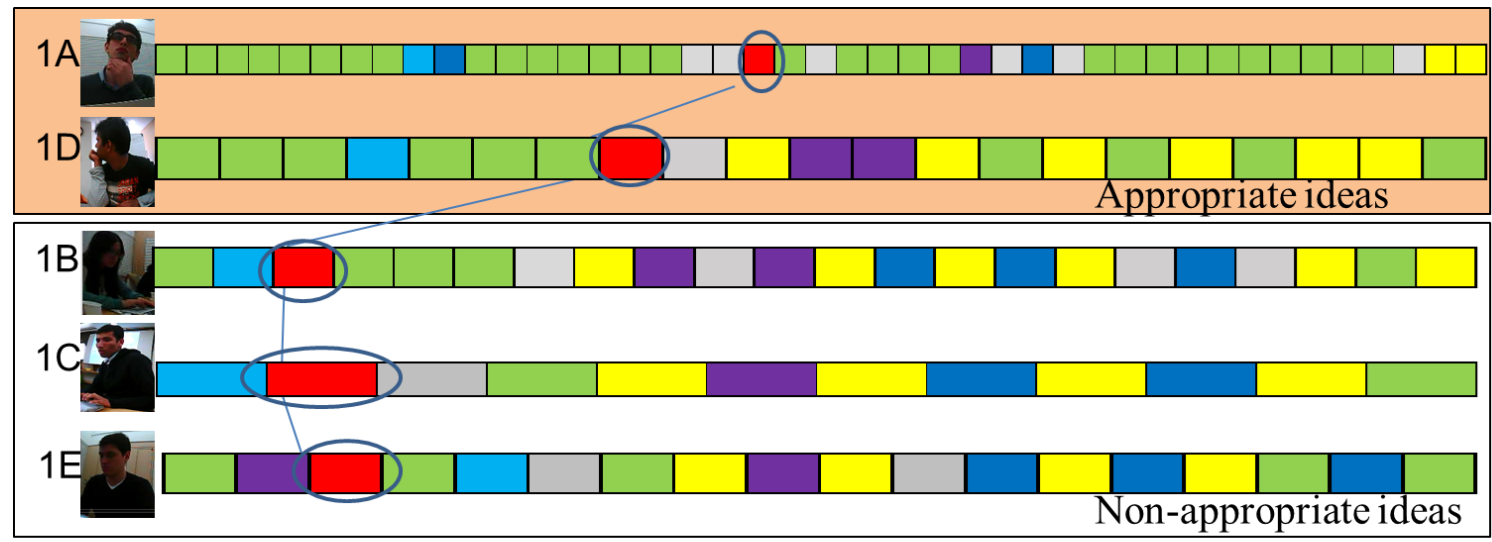

$\square$ Source retrieval $\square$ Domain setting $\square$ Domain refining $\square$ Structure $\square$ Creative leap $\square$ Title $\square$ others

Figure 4: Coding of individual participants' thinking processes in the generation task session

\section{Results}

For the generation task, the average number of notes created by participant is 22 ( $\min =12$, $\max =41$, std $=8.5$ ), and 20 ideas were created in total. The idea generation task was performed individually, so the unit of analysis is of individual participants.

From the four runs of the innovation workshop, 10 out of the 20 generated ideas were assessed as appropriate ideas using the evaluation method described above. As we can see from the results, analogical thinking does not always promote appropriate idea generation. Among the 10 participants who failed to generate an appropriate idea, five of them were able to import the structural features from the source cases, but unable to apply them to the new domain which is superficially 
far from the existing domains. The other five subjects failed to recognize the underlying structures of any source cases.

The degree of deliberation was defined as the number of notes created by a participant before reaching a creative leap divided the total number of notes created. According to the histogram analysis (see Figure 5), it was found that five participants had low level of deliberation, and the other 15 participants had high level of deliberation before reaching the creative leap moment, with $50 \%$ as the dividing point.

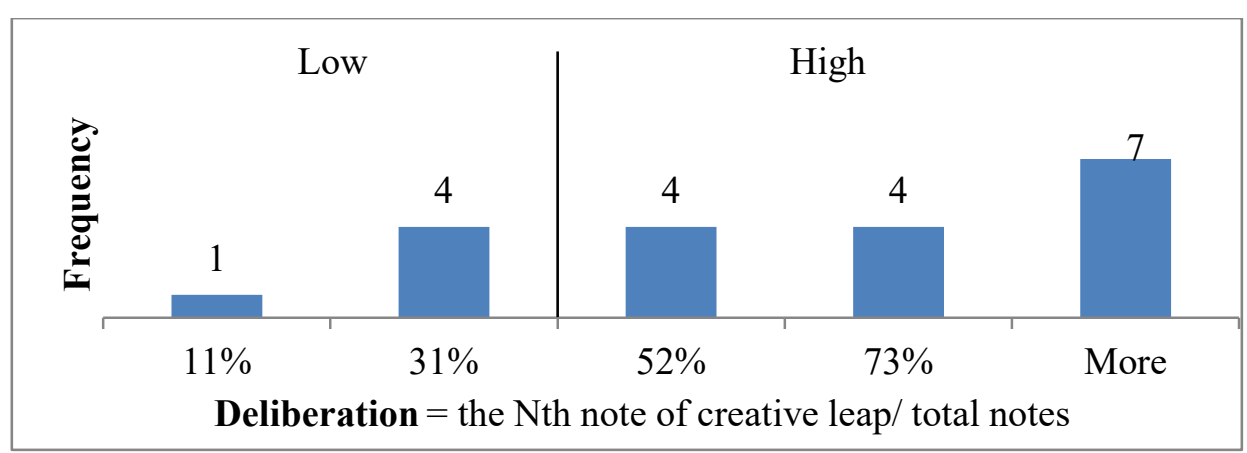

Figure 5: Distribution of participants by degree of deliberation

As results, the relationship between the deliberation before reaching the creative leap moment and the appropriateness of generated idea has been identified as shown in Figure 6-a). All the ten appropriate ideas were generated after a high degree of deliberation before reaching the creative leap moment. Although, deliberation correlates with the appropriateness of generated idea, it does not show a significant relationship $\left(\chi^{2}=2.222, \mathrm{df}=1\right.$, $\mathrm{p}$-value $\left.=0.136\right)$. Five out of fifteen participants who demonstrated a high degree of deliberation were still unable to generate an appropriate idea.

From the analysis of interview transcripts, we found that $50 \%$ of the subjects who generated an appropriate idea came up to their creative leap moments while alternating the domains for a new idea, as illustrated below:

"First, I thought about the homework coaching idea, but I didn't think it was novel, then I turned back to the mechanism I selected, then, I thought another idea about my own experience, and it could be solved with this mechanism." (Participant 2A)

"First, for the map-based database, I thought about the toilet information on the map, then when I see this bike map image, the Wi-Fi map came to my mind." (Participant 2B)

"My creative leap started with the medical examination idea, which came from the structure I choose, then I thought about the idea of shaking bed for alarm, then I turned to the blood donation idea." (Participant 3A)

The degree of trial and error was measured by the number of domains considered for generating a new idea. If a subject considered more than three domains, it is assessed as "high". Also, if a subject deleted his or her previous notes more than five times before writing the domain of new idea, it was also regarded as having trial and error. The results demonstrated that six out of twenty subjects showed a high degree of trial and error in deciding the domain for a new idea, and that all of them generated an appropriate idea as shown in Figure 6-b). Thus, it seems that having a high degree of trial and error before deciding the final domain for a new idea has a significant relationship with the appropriateness of a generated idea $\left(\chi^{2}=6.667, \mathrm{df}=1\right.$, p-value $\left.=0.0098\right)$. 
a)

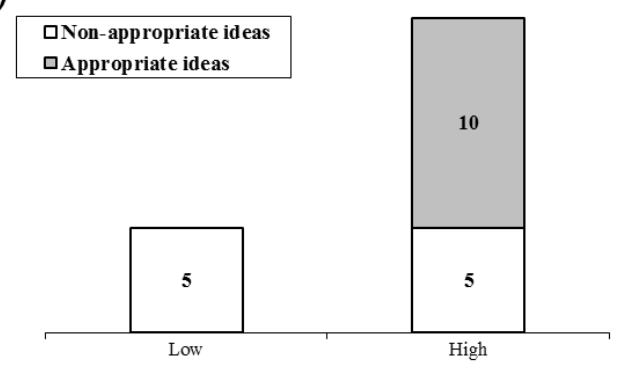

Degree of deliberation before reaching the creative leap stage

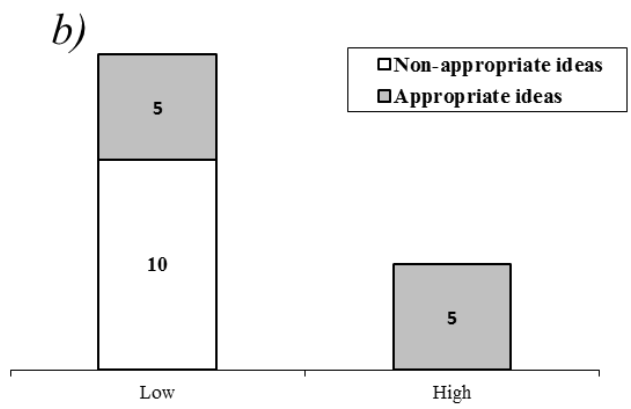

Degree of trial and error in finding the domain for a new idea

Figure 6: Relationship between the appropriateness of generated idea and a) deliberation before reaching the creative leap; b) having trial and error in finding a domain

From the results, it was found that having deliberation before reaching the creative leap moment and using the trial and error tactic in finding a domain for the new idea is crucial for generating an appropriate idea through analogical thinking.

Nevertheless, as we noticed from the results, people often neglect to take those crucial steps when generating ideas. Two-thirds of the participants failed to use the trial and error tactic in finding a domain for their new idea during the idea generation session. Of course, it is not easy to generate a new idea that exhibits a deep structural similarity but with little superficial similarity with the source ideas. Many studies suggested that when people face complex problems, they tend to focus on familiar ideas rather than making efforts to think creatively (Collins \& Loftus, 1975; Mednick, 1962; Tversky \& Kahneman, 1974). However, the findings of this study provide insights for developing training methods and workshops to help participants generate appropriate ideas by analogical thinking.

\section{Conclusion and Discussion}

Although numerous studies have proposed methods demonstrated to encourage people to create new ideas, there is a lack of research empirically identifying factors which enhance the appropriateness of generated ideas. This research focuses on analogical thinking and investigates the relationship between the thinking process in idea generation and the appropriateness of generated ideas. The results of this study suggest that a high degree of deliberation before reaching the creative leap moment and use of the trial and error tactic while finding the domain for a new idea enhances the appropriateness of generated ideas.

However, the findings of this study have some limitations mainly due to the small sample size. There were several restrictions in recruiting participants: they had to be English speakers, interested in the innovation workshop, willing to participate voluntarily, and with no previous experience of the workshop topic. The number of subjects is relatively small, and the participants were limited to in demographics to undergraduate or graduate students in their twenties or thirties who speak English as a second language. In future studies, more workshops need to be conducted to increase the size and diversity of samples to increase the generalizability and statistical significance of findings.

In addition, the topic of the idea generation task in this study was given to the participants, and it was confined to the collective intelligence service. During the workshop, subjects were allowed to select freely the domain of problem to be solved after attaining knowledge of the business mechanisms by reading a booklet of the 25 case studies and group discussion. However, in real life, there are many cases where the problem to be solved is in an unknown domain and the range 
of knowledge is limited. In future studies, the topic of idea generation tasks should be expanded based on the needs of participants, to include diverse fields such as new products development, social services, and personal behaviors.

Most importantly, there are issues in validating the proposed evaluation method. A possible reason for the lack of validation of an evaluation method is the philosophical and methodological problems involved in validating methods (Moody, 2003). Rescher (1977) claims that human knowledge consists of two types: 1) knowledge "that", which defines statements or assertions about the world; 2) knowledge "how", which defines ways of doing things. And he argues that an entirely different approach is required to validate methodological knowledge. Accordingly, if the methods have pragmatic value but not the value of truth, it cannot be proven true or false, but only determined effective or ineffective. In this case, the validity of a method can only be established by applicational success in practice. The objective of validation in our study should not be to demonstrate that the method is "correct", instead, it has rationales to apply the method based

on its pragmatic success. However, we should validate the proposed evaluation method by having trained raters test it in further studies. In spite of this limitation, our approach is important, not only because it reduces bias stemming from raters' subjectivity - a major weaknesses of current assessment methods, but also because it enables further studies of how people generate appropriate ideas by observing the whole ideation process.

\section{References}

Akin, Ö., \& Akin, C. (1996). Frames of reference in architectural design: Analysing the hyperacclamation (A-h-a-!). Design Studies, 17(4), 341-361. doi: 10.1016/S0142-694X(96)00024-5

Berlyne, D. E. (1960). Conflict, arousal, and curiosity (Vol. xii). New York, NY, US: McGraw-Hill Book Company.

Blanchette, I., \& Dunbar, K. (2000). How analogies are generated: The roles of structural and superficial similarity. Memory \& Cognition, 28(1), 108-124. doi: 10.3758/BF03211580

Boden, M. A. (1994). What is creativity. Dimensions of Creativity, 75-117.

Clement, J. (2008). Creative model construction in scientists and students: The role of imagery, analogy, and mental simulation: Springer.

Collins, A. M., \& Loftus, E. F. (1975). A spreading-activation theory of semantic processing. Psychological Review, 82(6), 407.

Connolly, T., Jessup, L. M., \& Valacich, J. S. (1990). Effects of anonymity and evaluative tone on idea generation in computer-mediated groups. Management Science, 36(6), 689-703.

Cross, N. (1997). Creativity in design: Analyzing and modeling the creative leap. Leonardo, 30(4), 311-317. doi: $10.2307 / 1576478$

Dean, D. L., Hender, J. M., Rodgers, T. L., \& Santanen, E. L. (2006). Identifying quality, novel, and creative ideas: Constructs and scales for idea evaluation. Journal of the Association for Information Systems, 7(10), 646-698.

Devadasan, P. (2011). Collaborative intelligence measure for knowledge based service industry. Purdue University.

Dorst, K., \& Cross, N. (2001). Creativity in the design process: Co-evolution of problem-solution. Design Studies, 22(5), 425-437. doi: 10.1016/S0142-694X(01)00009-6

Dunbar, K., \& Blanchette, I. (2001). The in vivo/in vitro approach to cognition: The case of analogy. Trends in Cognitive Sciences, 5(8), 334-339. doi: http://dx.doi.org/10.1016/S1364-6613(00)01698-3

Duncker, K. (1945). On problem-solving. (Psychological Monographs, No. 270.). Washington, DC, US: American Psychological Association. 
Falkenhainer, B., Forbus, K. D., \& Gentner, D. (1989). The structure-mapping engine: Algorithm and examples. Artificial Intelligence, 41(1), 1-63.

Finke, R. A., Ward, T. B., \& Smith, S. M. (1992). Creative cognition: Theory, research, and applications. Cambridge, MA: MIT Press.

Forbus, K. D., Ferguson, R. W., \& Gentner, D. (1994). Incremental structure-mapping. Paper presented at the Proceedings of the Cognitive Science Society, Atlanta, Georgia.

Forbus, K. D., \& Oblinger, D. (1990). Making SME greedy and pragmatic. Paper presented at the Proceeding the Cognitive Science Society, Cambridge, Massachusetts.

Gentner, D. (1983). Structure-mapping: A theoretical framework for analogy. Cognitive Science, 7(2), 155170.

Gentner, D., Brem, S., Ferguson, R. W., Markman, A. B., Levidow, B. B., Wolff, P., \& Forbus, K. D. (1997). Analogical reasoning and conceptual change: A case study of Johannes Kepler. The Journal of the Learning Sciences, 6(1), 3-40.

Gentner, D., \& Medina, J. (1998). Similarity and the development of rules. Cognition, 65(2-3), 263-297. doi: http://dx.doi.org/10.1016/S0010-0277(98)00002-X

Gick, M. L., \& Holyoak, K. J. (1980). Analogical problem solving. Cognitive Psychology, 12(3), 306-355.

Glynn, S. M., Britton, B. K., Semrud-Clikeman, M., \& Muth, K. D. (1989). Analogical reasoning and problem solving in science textbooks. In J. A. Glover, R. R. Ronning, \& C. R. Reynolds (Eds.), Handbook of Creativity (pp. 383-398): Springer.

Goldschmidt, G. (1995). Visual displays for design: Imagery, analogy and databases of visual images. Visual Databases in Architecture, 53-74.

Hesse, M. B. (1966). Models and analogies in science (Vol. 7). Notre Dame: University of Notre Dame Press

Hocevar, D. (1981). Measurement of creativity: Review and critique. Journal of Personality Assessment, $45(5), 450-464$.

Holyoak, K. J., Lee, H. S., \& Lu, H. (2010). Analogical and category-based inference: A theoretical integration with Bayesian causal models. Journal of Experimental Psychology: General, 139(4), 702-727. doi: $10.1037 / \mathrm{a} 0020488$

Holyoak, K. J., \& Thagard, P. (1989). Analogical mapping by constraint satisfaction. Cognitive Science, $13(3), 295-355$.

Holyoak, K. J., \& Thagard, P. (1996). Mental leaps: Analogy in creative thought. MIT Press.

Kintsch, W. (2001). Predication. Cognitive Science, 25(2), 173-202.

Koestler, A. (1964). The act of creation. Oxford, England: Macmillan.

Kogan, M. (2000). Higher education communities and academic identity. Higher Education Quarterly, 54(3), 207-216. doi: 10.1111/1468-2273.00156

Malone, T. W., Laubacher, R., \& Dellarocas, C. (2009). Harnessing crowds: Mapping the genome of collective intelligence. Rochester, NY: Social Science Research Network.

Mednick, S. (1962). The associative basis of the creative process. Psychological Review, 69(3), 220.

Minogue, K. R. (1973). The concept of a university. Transaction Publishers.

Moody, D. L. (2003). The method evaluation model: A theoretical model for validating information systems design methods. The Proceedings of European Conference on Information Systems, 79.

Perkins, D. N. (1997). Creativity's camel: The role of analogy in invention. In T. B. Ward, S. M. Smith \& J. Viad (Eds.), Creative thought: An investigation of conceptual structures and processes (pp. 523-538). American Psychological Association. 
Quinn, A. J., \& Bederson, B. B. (2011). Human computation: A survey and taxonomy of a growing field. Paper presented at the Proceedings of the SIGCHI Conference on Human Factors in Computing Systems.

Rescher, N. (1977). Methodological pragmatism: A systems-theoretic approach to the theory of knowledge. Blackwell.

Rhodes, M. (1961). An analysis of creativity. Phi Delta Kappan, 305-310.

Runco, M. A. (2014). Creativity: Theories and themes: Research, development, and practice: Elsevier.

Tversky, A., \& Kahneman, D. (1974). Judgment under uncertainty: Heuristics and biases. Science, 185(4157), 1124-1131. doi: 10.1126/science.185.4157.1124

Welling, H. (2007). Four mental operations in creative cognition: The importance of abstraction. Creativity Research Journal, 19(2-3), 163-177.

Winston, P. H. (1982). Learning new principles from precedents and exercises. Artificial Intelligence, 19(3), 321-350. doi: http://dx.doi.org/10.1016/0004-3702(82)90004-2

\section{Appendix: Source Cases and Generated Ideas}

\begin{tabular}{|c|c|c|}
\hline $\begin{array}{l}\text { Structural } \\
\text { category }\end{array}$ & Source cases & The title of generated ideas \\
\hline $\begin{array}{l}\text { I. Crowd- } \\
\text { sourcing }\end{array}$ & $\begin{array}{l}\text { Katariba café } \\
\text { Lang-8 } \\
\text { Conyac } \\
\text { Creative agency for everyone } \\
\text { Lancers } \\
\text { Kopernik } \\
\text { InnoCentive } \\
\text { Logo Tournament }\end{array}$ & $\begin{array}{l}\text { Soft loan for educating the poor } \\
\text { Quick geek fix } \\
\text { Fill out my forms } \\
\text { Job finder for graduate } \\
\text { Childcare } \\
\text { Services for educating minor groups } \\
\text { Job advisor }\end{array}$ \\
\hline Count & 8 & 7 \\
\hline $\begin{array}{l}\text { II. Human } \\
\text { computation }\end{array}$ & $\begin{array}{l}\text { Price.Com } \\
\text { Rakuten Travel, voice of users } \\
\text { at cosme } \\
\text { Tabelog } \\
\text { Wedding Park } \\
4 \text { travel } \\
\text { Yahoo Weather } \\
\text { Dating expert }\end{array}$ & \\
\hline Count & 8 & 0 \\
\hline $\begin{array}{l}\text { III. Social } \\
\text { computing }\end{array}$ & $\begin{array}{l}\text { Open ideo } \\
\text { User creating weather news } \\
\text { Bike lover's MAP } \\
\text { Cook pad } \\
\text { YOMIURI ONLINE Comments }\end{array}$ & $\begin{array}{l}\text { City microscope } \\
\text { Wifi finder } \\
\text { Moral and sex education }\end{array}$ \\
\hline Count & 5 & 3 \\
\hline
\end{tabular}




\begin{tabular}{lll}
\hline $\begin{array}{l}\text { Structural } \\
\text { category }\end{array}$ & Source cases & The title of generated ideas \\
\hline $\begin{array}{lll}\text { IV. Data } \\
\text { mining }\end{array}$ & KuraSushi & Ultimate movie recommendation \\
& Amazon.com & Blood donation \\
& Google Japanese Input & E-database for shopping mall \\
& POS system & Personal education \\
& 4 & Career change \\
\hline Others & & 5 \\
& & Beauty map \\
& & PET bottle finder \\
& & Cut\&fill \\
& & Immersive education in microworlds \\
& 0 & Elite education \\
\hline Total & 25 & 5 \\
\hline
\end{tabular}

\section{Biographies}

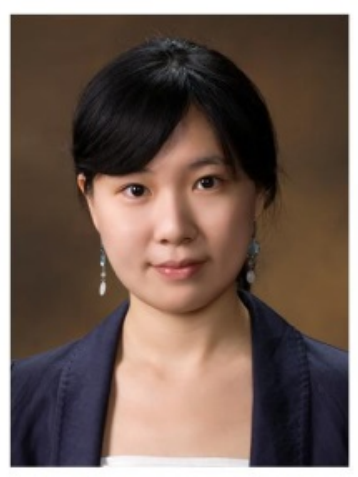

Eunyoung Kim is a postdoctoral researcher in Center for Knowledge Structuring at the University of Tokyo, Japan. She received her Ph.D. from the University of Tokyo in 2015. Her recent publications include "A Study on an Assessment Framework for the Novelty of Ideas Generated by Analogical Thinking", Procedia-Social and Behavioral Sciences (2015, vol.195c), and "Japanese Policy and Programs for the Fostering of Global Entrepreneurs", STI Policy Review (2016, Vol.7 No.1). Her research interests include workshop design, innovative educational programs, and thinking skills.

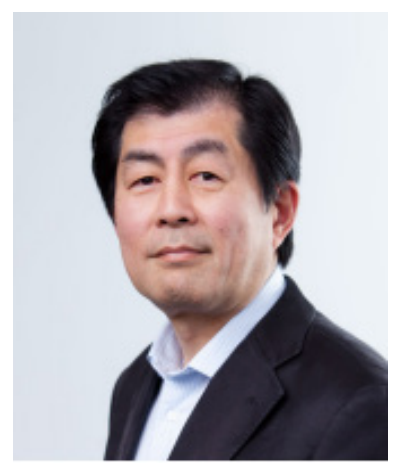

Hideyuki Horii is a professor in the Department of Civil Engineering as well as a director in Center for Knowledge Structuring at the University of Tokyo, Japan. He established the i.school to promote humancentered innovations through educational programs. He has published many research papers applied mechanics, rock mechanics, sociotechnology and books including "Socio-technology: Design of problem-solving”, University of Tokyo Press, 2012. 